\title{
Lexical stress in Modern Halh Mongolian
}

Yumei Sang

Department of Linguistics, Laboratory CLILLAC-ARP, Paris-Diderot University, France

https://doi.org/10.36505/ExLing-2011/04/0029/000198

\begin{abstract}
The purpose of this paper is to study lexical stress in Mongolian and its place of realization. Words and short declarative sentences are analyzed. We observe certain regularity in the rising of F0 on the most prominent syllables. We also show that duration is used as a correlate of stress in the sense that long vowels are privileged to receive stress: the stress falls on the syllable which contains a long vowel whatever its place within a word. In the case there is no long vowel, the stress falls on the second syllable. (Stress design here lexical stress).
\end{abstract}

Key words: Speech, prosody, stress, Mongolian, Halh

\section{Introduction}

The study focuses on the variety of Mongolian that is spoken in the Republic of Mongolia. There are different opinions on the nature and place of stress in Mongolian. Two prosodic units, the syllable and the more have been said to carry the stress:

1. Stress falls on the first syllable (Luvsanvandan 1976, 1986, Moomoo 1979).

2. Stress falls on the first syllable if it contains a long vowel. If the first syllable does not contain a long vowel, the stress falls on the second syllable (Harnuad2003).

3. There is no stress in Mongolian on the lexical level. Vowel harmony works as a rhythmic feature. A mora analysis is proposed (Svantesson and al. 2005, Karlsson 2005, Svantesson and Karlssson 2004).

4. We show that the stress falls on the syllable which contains a long vowel. In the case there is no long vowel, the stress falls on the second syllable.

The only consensus is that lexical stress is not distinctive in Mongolian: no minimal pairs can be found. In this paper, we will discuss these theories by studying the stress in Mongolian. The analysis takes into account a test that we have performed concerning the perception of the most prominent syllables. We will also discuss the length of the vowel.

ExLing 2011: Proceedings of 4th Tutorial and Research Workshop on Experimental Linguistics, 25-27 May, Paris, France 


\section{Corpus analysis}

The analysis is performed on a corpus composed of more than 70 single words and 50 short declarative sentences read by two Mongolian nativespeakers. For the corpus analysis, we used the signal processing software WinPitch.

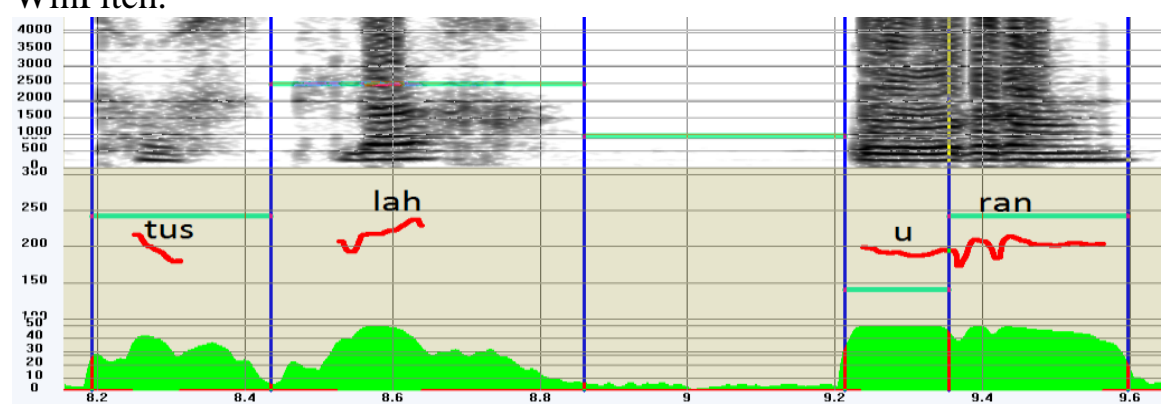

Figure1. Spectrogram of two utterances: "tuslah" (to help) and "uran" (artistic).

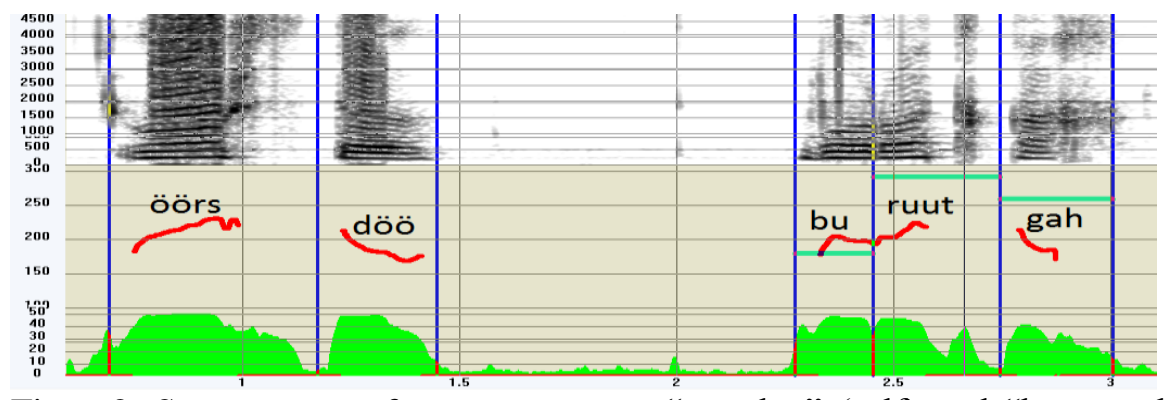

Figure2. Spectrogram of two utterances: "öörsdöö" (self) and "buruutgah" (to accuse).

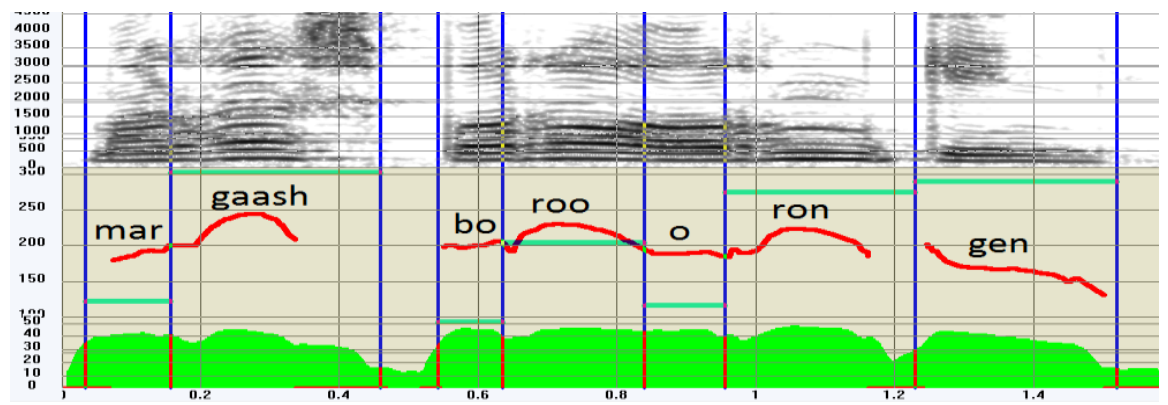

Figure3: Spectrogram of the utterance: "Margaash boroo oron gen" Tomorrow it will rain. Margaash-tommorw, boroo-rain, oron-fall.FUT. genfinal partical. 


\section{Results and discussion}

The utterances in the Figure1, do not contain any long vowel. We see that the stress falls on the second syllable both for "tuslah" (to help) and "uran" (artistic). In Figure2, we showed two words each containing a long vowel, "öördöö" (self) and "buruutgah" (to accuse). We see that there is a F0 rising on the first syllable of "ö̈rsdöo", which is a long vowel, and the second syllable of "buruutgah" which is also a long vowel. In Figure3, "Margaash boroo oron gen" (tomorrow it will rain), the spectrogram shows that the stress falls on the second syllable of "Margaash" and "Boroo" which both contain a long vowel. In "oron", there is no long vowel; we see a F0 rising on the second syllable. So in Figures 1 to 3, we see a F0 rising on the most prominent syllables. The priority place of stress is the syllable containing a long vowel and they may be in any position within a word. We also see that if a word contains no long vowel, the stress falls on the second syllable. This is observed throughout the entire corpus, with few exceptions probably due to word internal structure of these words. A more detailed study would be needed to explain these observations.

We believe that the historical development of vowels in Mongolian makes it difficult to investigate lexical stress, in the sense that Mongolian has undergone a major change at the lexical and phonetic level with arrival of the Cyrillic alphabet. In modern Mongolian, it seems that non-initial vowels, long or short, tend to be shortened. However, initial vowels keep their length because of their strong position in vocalic harmony. These length variations make it more difficult to analyze lexical stress in Mongolian. We think it could be why some previous theories (Karlsson, 2005), (Svantesson, 2005) have assumed that long vowels only appear in the initial position. Karlsson (2005) performed an investigation of vowel length, the results of which showed that a short vowel in the initial syllable has a length $60 \%$ that of a long vowel and a short vowel in the non-initial syllable has a length $72 \%$ that of a long vowel. These results do not conform to the principle of vocalic harmony which states that the initial vowel has a strong position because of its role of vowel assimilation of following syllables. We believe that the reason why the percentage of initial short vowel is lower than the percentage of the non-initial short vowel, (60\% vs $72 \%)$, could be that the non-initial short and long vowels were mixed in the analysis. Even if it is sometimes shortened, we think that the long vowel in non-initial syllable stays phonologically long because it receives the stress.

We also believe that the vowel length variation could explain these different theories on the lexical stress in Mongolian. 


\section{Conclusion}

In this paper, we have showed that the lexical stress is conventional in Mongolian and that its place of realization is governed by certain rules. A syllabic analysis is proposed: lexical stress falls in priority on the syllable containing a long vowel, regardless its position within a word. When there is no long vowel, stress falls on the second syllable. We showed that F0 rising is the most correlated patterns to signal prominence. We discussed also the duration of vowels in initial and non-initial position in the word, especially the status of non-initial reduced long vowels. We think that these vowels are phonologically long, since they receive the stress.

\section{References}

Harnaud, H. 2003. A Basic study of Mongolian prosody. Publications of the Department of Phonetics, University of Helsinki 45. Helsinki.

Karlsson, A.-M. Svantesson, J.-O. 2004. Prominence and mora in Mongolian. Speech Prosody, 65-58.

Karlsson, A.-M. 2005. Rythme and intonation in Halh Mongolian. Lund University.

Luvsanvandan, Sh. 1976. Orchin tsagiin mongol helnii butets(2). M\&D.

Luvsanvandan, Sh. 1986. Orchin tsagiin mongol helnii butets(1). M\&D.

Moomoo, S. 1979. Mongol helnii avia züi. MUIS.

Svantesson, J.-O. Tsendina, A., Karlsson, A., Franzén, V. 2005. The phonology of Mongolian. Oxford University Press. 